\title{
Manufacture and Characterization of Sensors for Optimizing the Detection of Water Contaminated by Sugar Mill Effluents in Waterways Around Sugar Mill
}

\author{
Eguh Budi Leksono*, Amar Hanif, Frida Agung Rakhmadi \\ Physics Department, Faculty of Science and Technology, UIN Sunan Kalijaga, \\ Jl. Marsda Adisucipto No 1 Yogyakarta 55281, Indonesia. Tel. +62-274-540971, Fax. +62-274-519739. \\ Email*: eguhleksono869@gmail.com
}

\begin{abstract}
Waste produced by sugar factories will affect the quality of water in the surrounding environment. The manufacture and characterization of sensors to optimize the detection of water contaminated by sugar mill effluents in waterways around sugar mills has been carried out. This study aims to create and characterize resistance sensors as an alternative tool to distinguish water polluted from sugar factory wastewater and clean water from sugar mill waste. The method used in this study is the Arduino UNO-based water resistance sensor method which is carried out in three stages, the first is the preparation of tools and materials, the second is data retrieval, and the third is data processing. This study uses a water resistance sensor, Arduino UNO as a controller, and also equipped with LED indicators. The results showed that the Arduino UNO-based water resistance sensor can be used as a tool to distinguish water contaminated by sugar mill waste and clean water from sugar mill waste.
\end{abstract}

Keywords: Waste water, Arduino UNO, Water resistance.

\section{INTRODUCTION}

Industry as a motor of development in a country's economy is an important part of people's lives in various countries. Industry helps meet the needs of the wider community through its ability to do mass production. Like two-sided coins, in addition to facilitating people's lives, industrial processes also risk damaging the environment. This is because in carrying out their production, the industry produces by-products in the form of solid, liquid, or gas waste. Generally, the amount of waste produced by the industry is linear or directly proportional to the amount of production.

Characteristics of the sugar industry liquid waste, depending on the minimization and reuse of the water, can be seen from the wastewater that is generally produced: sugar cane washing water, mill waste water, condenser waste water, boiler blowdown water, spill juice, ash water, waste acidic and corrosive, water used for washing floors and other waste water. The main pollutants in the waste are BOD5, COD, pH, TSS and water with a relatively high temperature (Water Environment Federation, 2008). Water polluted by organic waste, especially waste originating from the food processing industry, is a fertile place for the proliferation of microorganisms, including pathogenic microbes. Pathogenic microbes that proliferate in polluted water that causes the emergence of various diseases are very many and all of them are diseases that can be transmitted easily. (Wardhana, 2004). The purpose of this study was to analyze the difference between water contaminated by sugar factory wastes and clean water from sugar mill wastes by the voltage method of Arduino-based water resistance sensors

\section{MATERIALS AND METHODS}

This research was conducted through three stages, namely the preparation of tools, data collection and data processing. Materials that need to be prepared are two samples, namely water contaminated by sugar factory waste and clean water from sugar factory waste. The instrument used in data collection is called Arduino UNO, LED, water resistance sensor and $500 \mathrm{ml}$ measuring cup. After the preparation of tools and materials has been prepared, then the data collection. The process of taking data uses Arduino UNO-based water resistance sensors. Data collection aims to measure surface tension. The principle of this tool is the force required to release an iridium platinum ring when dipped on a surface proportional to the surface tension of the liquid.

Data collection was carried out by varying the measurements 5 times, the data collection process was carried out in a basic physics laboratory with room temperature of $27^{\circ} \mathrm{C}$ and room humidity of $55 \%$. For this reason, data retrieval is only dipped for 2 seconds to avoid electrolysis of the water. The data that has been obtained is then analyzed how its characteristics can then be used to find out whether the data can be continued for making detection devices or not. If the data obtained is intersected, then the data cannot be used to create a detection system. If the data obtained is not intersected 
or there is a difference, it can be continued or used to create a detection system. After that, look for the average voltage value from the sample by entering the value of the sample data into the following equation:

$$
\overline{\mathbf{V}}=\frac{\sum \mathbf{V i}}{\mathbf{N}}
$$

$\bar{V}$ is the average voltage and $\mathrm{N}$ is the number of measurements. After obtaining the average value of the voltage, proceed with determining the uncertainty value of the experiment using the equation below (Morris, 2014);

$$
\Delta \bar{V}=\frac{1}{n} \sqrt{\frac{n \sum V i^{2}-\left(\sum V i\right)^{2}}{N-1}}
$$

while for sensor characteristics to get repeatability values, the following equation is used :

$$
\text { Repeatibility }=\frac{\mathrm{K}-\mathbb{} R}{\mathrm{~K}} \times 100 \%
$$

Where $\bar{R}$ is the average value of resistance and $\Delta R$ is the uncertainty value. To get the accuracy value, use equation as .

$$
\begin{gathered}
\beta=\frac{|R-\tilde{R}|}{R} \times 100 \% \\
\text { Accuracy }=100 \%-\beta
\end{gathered}
$$

Where $\mathrm{R}$ is the actual resistance value according to the resistor and $\bar{R}$ is the average resistance value.

\section{RESULTS AND DISCUSSION}

\section{Hardware design}

Hardware design starts with designing a series of devices by integrating several devices and sensors into a system. This sensor requires a power supply that is connected to the Arduino UNO, then a $22 \mathrm{k}$ ohm resistor. The resistance sensor is connected to pins A0 and GND, as an indicator the LED is used connected to pin 4. The sample will function as an intermediary for the voltage flow where the voltage value is $5 \mathrm{~V}$. The results of the design that has been designed with the Fritzing software can be seen in $\mathrm{f}$

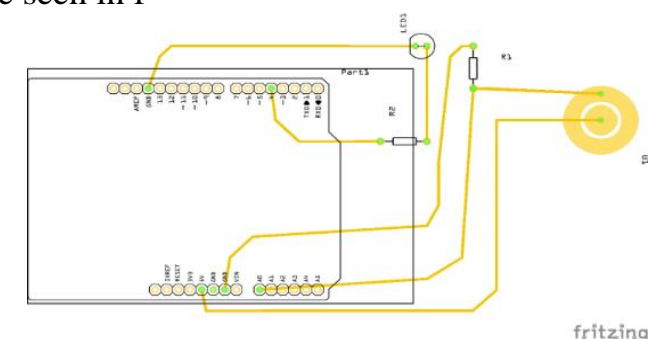

Figure 1. The scematic circuit sensors.

\section{Software Design}

Software design is an important component in making this tool so software design needs to be done to be able to maximize hardware performance. The design of the software is done by making sure the workflow design of the tools is appropriate, then proceed with designing the programming algorithm. The software flow diagram is built like the figure 2 .

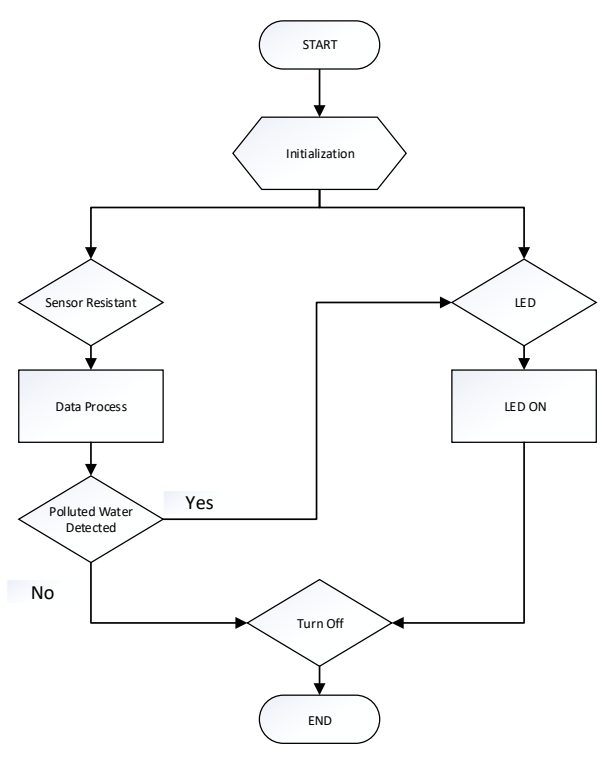

Figure 2. Flowchart of Arduino.

\section{Characterization Sensor}

After design and manufacture stage is done, the first stage of the sensor is used to measure the original resistor whose results are illustrated in Figure 3.

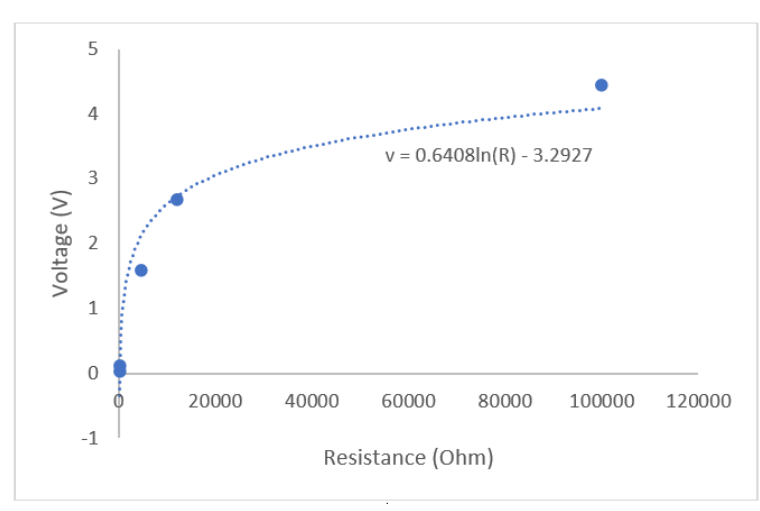

Figure 3. Transfer function of sensor with factory-made resistor.

Obtained a resistance value where the greater uncertainty along with the increasing value of the resistor resistance. In this characterization test the precision is $98 \%$. However, at the low resistance value there needs to be special treatment because the low resistance value will be increasingly difficult to compute. 
But in high value resistance accuracy can be trusted because the value is high.

\section{Discussion}

The testing process is carried out on the whole system to ensure that the overall system performance is working properly. To get the resistance data, the test is done by observing the value of the voltage results from the sample of water contaminated with waste and clean water which can be seen in Table 1:

Table 1. The Characterization Calculation Results

\begin{tabular}{cll}
\hline Volume $(\boldsymbol{m l})$ & $\begin{array}{l}\text { Polluted water } \\
(\overline{\boldsymbol{V}} \pm \Delta \overline{\boldsymbol{V}})\end{array}$ & $\begin{array}{l}\text { Clear Water } \\
(\overline{\boldsymbol{V}} \pm \Delta \overline{\boldsymbol{V}})\end{array}$ \\
\hline 100 & $2,588 \pm 0,0144$ & $2,468 \pm 0,0456$ \\
200 & $2,44 \pm 0,052$ & $2,056 \pm 0,0512$ \\
300 & $2,222 \pm 0,0104$ & $1,936 \pm 0,0368$ \\
400 & $2,122 \pm 0,0144$ & $1,63 \pm 0,024$ \\
500 & $1,942 \pm 0,0184$ & $1,5 \pm 0,004$ \\
\hline
\end{tabular}

Analysis of the data from this study was obtained in the case of polluted water, density and density were responsible for the amount of surface tension. Polluted water which is the result of the disposal of sugar factory waste will have a greater mass density. Based on the results of data processing contained in table 1.1 , it is proven that the voltage of water polluted by waste is greater than clean water. This is consistent with the theory that the amount of stress is influenced by several factors, such as the type of liquid, temperature, pressure, density, solute concentration, and density.

From the results of data processing shows samples of polluted water effluent from sugar factory and berish water do not overlap, where the sample of polluted water is in the range of the average value of the strain. The data can be clearly distinguished from the voltage value. Therefore, from this data can be used as a basis for making detection systems.

\section{CONCLUSION}

Based on testing can be that the Arduino-based water resistance sensor is able to differentiate water contaminated from sugar factory waste and clean water from sugar mill waste. This is very helpful to provide quick information to find out water polluted water and clean water from waste in the vicinity of the sugar factory area. people will be able to know the conditions for certain, because this technology is quite simple and easy to operate so that every surrounding community can know the changes that occur.

Developments that can be done, including making the system can be developed again using sensors that have a better level of sensitivity. After that, there needs to be standardization between the tools that have been made with existing tools. There are several ways that might be done when giving water capacity when doing tests that can support the level of measurement success.

\section{REFERENCES}

Abdullah, Mikrajuddin. 2017. Fisika Dasar II. Bandung Institute of Bandung, Bandung.

Fraden, Jacob. 2014. Hand Book of Modern Science, Third Edition. Advance Monitors Corporation, San Diego, California.

Morris, Alan S. \& Langari, Resa. 2014 Measurement and Instrumentation. Elsevier, India. 
THIS PAGE INTENTIONALLY LEFT BLANK 